\title{
TEMPO MESSIÂNICO: o verdadeiro estado de exceção
}

\author{
Temps messianique: le véritable état d'exception
}

Bárbara Canto ${ }^{1}$

\begin{abstract}
RESUMO: A intenção deste artigo é apresentar uma concepção diferente das usuais no que tange a temática do tempo messiânico. Será tratada a definição de Estado de exceção feita pelo filósofo alemão Carl Schimitt, pois entendemos que essa definição dialoga profundamente com a questão que Benjamin trata em seus textos, dada a contemporaneidade dos dois filósofos, das questões análogas das quais se ocupavam, e, sobretudo, por conta do contexto político em que viviam e que marcou de modo muito determinante seus escritos. E, como em Schimitt não se pode falar de Estado de exceção sem falar de seus conceitos de soberania e soberano, trataremos um pouco destes também, sem, no entanto, nos aprofundarmos neles. Nossa intenção é apresentar tais conceitos e depois problematizá-los com as questões benjaminianas. Feito isso, buscaremos apresentar de que maneira Benjamin trata tais concepções e como o tema do Tempo Messiânico se encontra enraizado em sua obra, porém tendo nos concentrando nas Teses sobre Conceito de História, onde o tema do messianismo subjaz. Traremos ainda a visão de dois comentadores para enriquecer nossa pesquisa, por se tratarem de visões extremamente interessantes e contribuírem substancialmente sobre este tema. Por último tentaremos sintetizar a influência que tais comentadores deixaram em nossa pesquisa e buscaremos formular o que para nós significa o Tempo Messiânico e o porquê dele ser o verdadeiro Estado de Exceção defendido e almejado por Walter Benjamin. Seu início e consumação, no entanto, será defendido aqui de forma diferente da dos comentadores utilizados.
\end{abstract}

Palavras-chave: Messianismo. Materialismo histórico. Filosofia Política.

RESUMÉ: L'intention de cet article est de présenter une conception différente de celles habituelles concernant le thème du temps messianique. la définition de l'état d'exception par le philosophe allemand Carl Schmitt sera traitée, nous comprenons que cette définition des dialogues profonds avec la question que Benjamin est dans leurs textes, compte tenu de la contemporanéité des deux philosophes, des questions similaires sont occupés, et en particulier, à cause du contexte politique dans lequel ils vivaient et qui marquait de façon très déterminée leurs écrits. Et, comme dans Schmitt ne peut pas parler de l'état d'exception sans parler des

\footnotetext{
${ }^{1}$ Mestranda do programa de pós-graduação em filosofia pela UFPR. E-mail: barbynascimento@gmail.com
} 
concepts de souveraineté et souverain, nous traiterons certains d'entre eux aussi, sans toutefois plonger en eux. Notre intention est de présenter de tels concepts puis de les problématiser avec les questions de Benjamin. Une fois cela fait, nous chercherons à présenter comment Benjamin traite ces concepts et comme le thème du temps messianiques est enraciné dans son travail, mais ayant en se concentrant sur les thèses sur le concept d'histoire, où le thème de la base messianisme. Nous apporterons également la vision de deux commentateurs pour enrichir notre recherche, car ce sont des visions extrêmement intéressantes et contribuent largement à ce sujet. enfin essayer de synthétiser l'influence que ces commentateurs ont laissé dans nos recherches et chercher à formuler ce que nous entendons temps messianiques et pourquoi il est l'état réel d'exception défendions et poursuivi par Walter Benjamin. Son début et sa consommation, cependant, seront défendus ici différemment de celui des commentateurs utilisés.

Mots-clés: Messianisme. Le matérialisme historique. Philosophie politique.

\section{QUEM DECIDE NO ESTADO DE EXCEÇÃO}

Por estado de exceção entende-se habitualmente como sendo um momento especifico no decorrer político de determinada região em que em um grave momento de crise, onde as instituições políticas e jurídicas encontram-se em uma tal desordem que acabam levando à suspenção das normas gerais desta região, necessitando assim, de um novo ordenamento jurídico afim de que este possa resolver o tal momento de crise ao qual esta região encontra-se imersa.

Em Carl Schimitt, no entanto, o estado de exceção é por sua vez, um "concepto general de la doctrina del Estado, no un decreto de necesidad cualquiera o estado de sitio" (SCHIMITT, 2009, p.13). Isto quer dizer que para Schimitt, dentro do ordenamento jurídico do Estado, o estado de exceção é previsto e tem sua delimitação jurídico-política definida, o que o torna diferente do estado de sítio onde não se possui nenhum aparato jurídico e/ou político, e as normas encontram-se suspensas.

Mas ainda que esteja previsto no ordenamento jurídico, para que haja este novo ordenamento, é necessário que se estabeleça primeiramente a ordem e, apenas uma figura tem força suficiente para isso, apenas ela é capaz de tal empresa, a saber, o Soberano. 
Para Schimitt apenas o soberano é capaz de retomar à ordem, pois só ele possui o real poder de decisão no Estado; em suas palavras, "El soberano crea esa situación y la garantiza en su totalidad. El asume el monopolio de la última decisión. El soberano crea esa situación y la garantiza en su totalidad. En lo cual estriba precisamente la esencia de la soberanía del Estado." (SCHIMITT, 2009, p. 18). Com isto Schimitt defende que para que se restaure a ordem é preciso que o poder político, jurídico, institucional se concentre nas mãos de uma única pessoa, para que esta possa de fato, exercer seu desígnio, isto é, restabelecer a ordem; e para isto é necessário que essa mesma pessoa não esteja submetida a entraves burocráticos, ela tem que estar acima de qualquer coisa que a limite, que a impeça de restabelecer a ordem, o que em última instância, faz com que o ordenamento jurídico que rege a sociedade como um todo, não se aplique a ela.

É importante aqui que seja ressaltado o contexto histórico-político. Vejamos: Schimitt escreve a Teologia Política, na qual define o que são as categorias estado de exceção e soberania em 1922. Momento em que a Alemanha, passa por uma forte turbulência econômica, em que uma hiperinflação derrubou o valor do Marco alemão e o país que ainda tentava se recompor depois da derrota da I guerra vê seu dinheiro se desvalorizando cada vez mais e seu modo de vida se perder nesse contexto. $^{2}$

Por outro lado, Agamben relata que Schimitt escreveu sobre tais assuntos como forma de responder aos conceitos benjaminianos de violência "pura" ou "revolucionária", os quais Benjamin problematizou no artigo encomendado pela revista alemã Die Weißen Blätter, na qual seria tratada a questão da violência; o título do artigo é Sobre a crítica do poder como violência (1921). Neste artigo Benjamin trata da relação entre o poder e a violência, de como esta se alimenta daquele e vice versa. Benjamin utiliza no título do texto um termo em alemão, Gewalt, que significa tanto poder como violência. Numa nota introdutória à leitura do artigo, o tradutor e organizador do livro Walter Benjamin, o anjo da história João Barrento, atenta para a polissemia do termo: "subjacente à palavra portuguesa 'poder' estará, por isso, quase sempre também a implicação da violência, e nas passagens que se usa 'violência' ela é também implicitamente a violência do poder" (BARRENTO 2012, p. 57).

\footnotetext{
${ }^{2}$ Para uma maior compreensão da hiperinflação da Alemanha nessa época ver, Costantino BrescianiTurroni, The Economics of Inflation (Nova York: Augustus M. Kelley, 1968).
} 
Neste texto, o que Benjamin procura demonstrar é como um se serve do outro (violência e poder) na manutenção do Direito, entendido nele como Direito Natural que se opunha ao Direto Positivo, como ele por muitas vezes se utiliza desses expedientes para manter a ordem e o status quo. Por sua vez, Schimitt defende que essa seria uma legítima ferramenta utilizada pelo Direito para a manutenção da ordem e que terá na figura do Soberano sua maior aplicabilidade.

$\mathrm{Na}$ defesa de um estado de exceção, Schimitt incluiu e submeteu todos os tipos de violência ao Direito positivo, ou seja, submeteu direitos tidos como inalienáveis, como mais especificamente o direito à vida, à estrutura jurídica, o que transformou o sistema judicial em uma "máquina de matar", segundo Agamben, criando assim a condição para a existência do Homo sacer ${ }^{3}$.

Exatamente por que caberia agora ao Direito considerar se determinado indivíduo e suas práticas possam vir a ser prejudiciais à manutenção da ordem, e se assim for, o Estado ou o Soberano passam a ter legitimidade para extirpar tal perigo. O que em última instância criou as condições que teriam levado a Alemanha a cometer um dos maiores crimes contra a humanidade. Neste sentido, Schimitt teria conseguindo dar uma autoridade teórica e um respaldo filosófico ao que mais tarde será feito pelo partido nacional-socialista e seu soberano, como forma de justificar o direito à dominação por parte da Alemanha dos povos considerados inferiores.

Antes, porém, de adentrarmos em terreno pantanoso e de nos perdermos em julgamentos, passemos a entender o que significou tais teorias no campo filosófico.

\section{O PARADOXO DA EXCEÇÃO}

A exceção pode ser entendida como uma espécie de exclusão na medida em que, quando suspende um ordenamento jurídico, exclui todo indivíduo que se encontrava em relação com ele. Esta dimensão coloca em si questões bastante problemáticas: 1) se ela é exclusão de tudo, de todo ordenamento jurídico, então nem mesmo ela poderia ter vigência, ou seja, se o aparato jurídico anterior foi suspenso, como ficam aqueles que estavam em relação, seja em forma de dívida, ou não, com ele, como tratá-los agora no novo ordenamento, já que sua ligação com

\footnotetext{
${ }^{3}$ Homo sacer é uma figura obscura da lei romana: uma pessoa que é excluída de todos os direitos civis, enquanto a sua vida é considerada "santa" em um sentido negativo. O indivíduo pode também ser matável por qualquer um.
} 
este não mais há?; 2) E o papel do soberano, no momento em que dá validade jurídica às relações, não se submete à lei, está, fora dela, mas ao mesmo tempo dentro, uma vez que é ele quem designa o aparato jurídico?

Prevendo que se poderia chegar a tais conclusões e que elas poderiam ser mal interpretadas, Schimitt ensaia uma resposta que, no entanto, não responde exatamente e cria mais uma situação problemática. Segundo ele não é porque está suspenso (o ordenamento jurídico anterior), que o sujeito está sem relação com a norma, ao contrário, é justamente nesse sentido que se dá sua relação. O que quer dizer o seguinte: no momento da suspenção da norma (proclamação do estado de exceção), todo aquele que se encontrava em relação com ela (antiga norma), e testemunha a ruptura dessa relação, não vai parar num assim chamado estado límbico. Sua nova posição se dará exatamente nesse sentido, ou seja, na posição de alguém que se encontra fora do novo ordenamento jurídico. Essa será sua nova relação com o Estado. Exatamente o que Agamben definiu como "relação de exceção", e que como foi exposto anteriormente, criou a condição do Homo sacer. Ele diz, "Não é a exceção que se subtrai à regra, mas a regra que suspendendo-se dá lugar à exceção, e somente desse modo se constitui como regra, mantendo-se em relação com aquela" (AGAMBEN, 2002, p. 26). Em outras palavras, sua relação com a norma agora é a de um indivíduo marginal, ou seja, alguém que se encontra à margem do novo aparato jurídico, sem os direitos, deveres e garantias jurídicas daqueles que estão, digamos dentro do novo aparato jurídico. O que levará uma quantidade considerada de pessoas a uma situação de incerteza a respeito de seus direitos e deveres bastante perigosa.

E por fim, com o intento de justificar a situação heterodoxa do Soberano, como a figura acima da lei e a fim de evitar questionamentos perturbadores, Schimitt elege a Soberania como um conceito limite. Ou seja, o soberano e apenas ele, seria aquele sujeito que se encontra no limiar do decurso histórico, pois somente ele que se encontra de maneira tão singularmente constituída no regimento de uma sociedade que possui o poder de estar ao mesmo tempo, dentro e fora do ordenamento jurídico, o que de certa forma pode-se pensar que é o Soberano o próprio Estado, exatamente por ser ele, "quien decide sobre el estado de excepcion" (SCHIMITT, 2009, p. 13).

Portanto, segundo a visão de Schimitt, ainda que num primeiro momento tenha-se esse estado em que a norma antiga não tenha validade, cabe ao soberano 
que é a figura que de fato melhor representa essa situação, por ser aquele que está fora da norma e que ao mesmo tempo quem dá a ela sua validade, dado que sua decisão é a norma; aquilo que era para estar submerso no caos passa a ter um novo ordenamento jurídico vigente e atuante, encarnado em uma pessoa.

No entanto, tal concentração de poder nas mãos de um único homem poderia levar a um Estado totalitário, diria algum humanista que por acaso se deparasse com tal situação, mas para isto também Schimitt elaborou uma resposta, Agamben a cita,

Em Schimitt, a soberania se apresenta na forma de uma decisão sobre a exceção. A decisão não é aqui a vontade de um sujeito hierarquicamente superior a qualquer outro, mas representa a inscrição no corpo do nómos, da exterioridade que o anima e lhe dá sentido. O soberano não decide sobre o que é licito e ilícito, mas a implicação originária do ser vivente na esfera do direito (AGAMBEM, 2002, p. 33).

Sua tentativa [a de Schimitt aqui descrita por Agamben] é de dar uma delimitação para o poder irrestrito do Soberano, como alguém que buscasse cuidar apenas do formalismo inscrito no Direito, ou seja, não cabe a ele decidir sobre o que é lícito ou ilícito, pois não é ele quem formula a lei, ele faz cumprir sua aplicação, e sobretudo, como tais concepções (lícito e ilícito), serão assimiladas e observadas (ou não) pela população que governa.

Ainda resta uma última questão no meio de tudo isto que é: como fica a situação da lei dentro desse estado, em que há aqueles que estão em relação com ela de diferentes formas: aqueles que estão "fora" dela, aqueles que não se submetem a ela e todos os outros que tentam apenas não entrar em desacordo com ela.

Agamben em A potência do pensamento (2005) retoma uma conversa entre Benjamin e Scholem sobre o romance de Kafka, O processo, para tratar dessa questão. Nesta conversa Benjamin chega à conclusão de que nesse romance a definição do estado da lei é que esta vige mas não significa e utiliza um termo em alemão, Geltung ohne Bedeutung (vigência sem significado) para designar tal situação jurídica. Scholem no entanto, discorda. Mas o que interessa aqui é que a partir disso Benjamin passa a utilizar essa expressão "vigência sem significado" para definir o estado da lei dentro do estado de exceção, algo que vige, mas não significa, ou seja, algo com forma, mas sem conteúdo. 
Feita essa exposição sobre o significado de soberania e estado de exceção, vejamos como Benjamin trata desse assunto e quais respostas ele dá a este tema tão instigante.

\section{O ESTADO DE EXCEÇÃO COMO REGRA}

Benjamin em sua última e mais polêmica obra, as Teses sobre o conceito de história (1940), delineia, entre outras coisas, a forma como a história vem sendo contada sempre sob a perspectiva dos vencedores, como esta não seria a maneira correta de contar a história e como cabe ao verdadeiro historiador fazer a inversão desta narrativa (contar a história a contrapelo).

$\mathrm{Na}$ oitava tese ele afirma que vivemos em um estado de exceção, e, além disso, fala que "o estado de exceção em que vivemos é a regra" (BENJAMIN, 2002, p. 245). Mas o que exatamente isso quer dizer? Qual o valor crítico dessa teoria?

Sabemos (se aceitarmos a proposição de Benjamin) que a história é contada sempre pelos vencedores, suas façanhas e artimanhas são exaustivas e repetidamente detalhadas para que sua glória não seja nem um pouco diminuída, para que fique demonstrada como sua força fora sobreposta àqueles que ousaram lutar e fracassaram na luta e, principalmente, para que sejam desencorajadas quaisquer tentativas de oposição a eles.

Nesse sentido, que a história venha sendo contada desta maneira é sabido, o que não se sabe, justamente por que não se pergunta e que é de extrema importância ao menos na filosofia benjaminiana é, qual foi o preço dessa vitória? E os vencidos? Em algum momento foram ouvidos, puderam expor suas razões, puderam 'falar', explicar suas motivações para a luta?

Desta forma, o que se tem, é que durante todo o decurso da história o que encontramos é a vitória das mesmas classes que sempre tiveram o domínio dos meios políticos e econômicos e com isso, detiveram o poder de fato. O que se pretende por História não passa de uma sucessão ininterrupta de vitórias desta classe. Benjamin trava um combate com o inimigo de seu tempo, o fascismo, que é só uma forma diferente de apresentação utilizada pelas mesmas classes detentoras do poder para garantir a perpetuação deste poder. É claro que numa escala de violência e negação de direitos civis de forma nunca antes vista. Fato histórico é que 
para Benjamin trata-se sempre da mesma classe apenas como uma nova roupagem. Por isso que na sexta tese ele fala que o "inimigo não tem cessado de vencer" (BENJAMIN, 2012, p.12), exatamente por que o inimigo continua o mesmo.

Mas de que forma pode-se combater esse inimigo? Segundo Benjamin, entre outras coisas, através da rememoração Erinnerung do passado, da luta daqueles que sucumbiram em nome de ideais humanos e políticos, mas que não estavam consoantes com o que desejavam as classes detentoras do poder; é através da rememoração do passado, passado que poderia ter sido e não foi e que cabe a cada geração honrá-lo.

A cada geração é concedida a oportunidade de resgatar esse passado suprimido e silenciado. O que faz com que ao longo da história se constitua uma ligação entre as gerações, tornando-as irmãs e dando sempre a atual a responsabilidade de libertar a anterior dos sofrimentos vividos. Segundo Benjamin:

O passado traz consigo um index secreto, que o remete para a redenção. Não passa por nós um sopro daquele ar que envolveu os que vieram antes de nós? Não é a voz a que damos ouvidos um eco de outras já silenciadas? As mulheres que cortejamos não tem irmãs que já não conheceram? A ser assim, então existe um encontro secreto entre as gerações passadas e a nossa. Então fomos esperados sobre esta Terra. Então foi-nos dada, como a todas as gerações que nos antecederam, uma tênue força messiânica a que o passado tem direito. Não se pode rejeitar de ânimo leve esse direito. (BENJAMIN, 2012, pág. 10)

É justamente por sermos dotados de uma força messiânica (segundo Benjamin) que seremos capazes de redimir o passado, de reescrever a história, de libertar os que vieram antes de nós e nós mesmos de todo sofrimento vivido pela nossa e pelas gerações anteriores.

$\mathrm{Na}$ oitava tese Benjamin dá uma dica de como é possível realizar tais atos. Ele diz que "nossa tarefa é provocar o verdadeiro estado de exceção", que "temos de encontrar um conceito de história que corresponda a esta ideia" (BENJAMIN, 2012, pág. 13), pois que só assim nos fortaleceremos e combateremos o inimigo, só assim seremos capazes de fazer frente a ele.

Mas o que isso quer dizer? Como se instaura o verdadeiro estado de exceção? Traremos aqui a versão de alguns de seus principais comentadores para elucidar tal questão. 


\section{O TEMPO MESSIÂNICO E O ESTADO DE EXCEÇÃO}

Para Agamben o verdadeiro estado de exceção que Benjamin deseja provocar, se dá com a chegada do Tempo Messiânico, pois só ele tem a força de "suspender a Lei":

O acontecimento messiânico significa acima de tudo uma crise e uma transformação radical de toda ordem da Lei (...). O Reino Messiânico, não é uma categoria entre outras no interior da experiência religiosa, mas é antes seu conceito limite. (AGAMBEN, 2015 p. 226).

O que quer dizer que, com a chegada do Messias e a restituição do novo mundo, sua confrontação se dará com a Lei, esta será restituída pela nova Tábua de Leis, e o próprio tempo irá parar. Ainda segundo Agamben, o Messias é de fato a figura em que a religião se confronta com o problema da "Lei", faz com ela um "ajuste de contas decisivo", por isso o advento do Messias não se trata apenas de uma questão teológica, mas principalmente política. No momento de sua chegada o Messias não apenas restituirá uma glória perdida, mas ressignificará toda a ordem social e jurídica. Sua chegada coincidirá com o Tempo histórico e o abolirá.

Por outro lado, a interpretação da pesquisadora da Unicamp J. M. Gagnebin deste mesmo tema nos remete a outra direção. Para ela, a vinda do Messias não irá abolir o tempo histórico, mas o suspenderá. Não se trata da suspenção de um mundo para o surgimento de outro, pois não haverá mais distinção entre esses mundos. Segundo sua leitura, o Messias virá restituir no mundo profano/histórico o novo mundo onde a dicotomia profano/sagrado não mais existirá. Eis o que ela diz: "o Messias chega, portanto, quando sua vinda se realizou tão integralmente que o mundo já não é nem profano nem sagrado, mas liberto - sobretudo da separação entre profano e sagrado". (GAGNEBIN, 2014, pág.192).

Para tal interpretação ela se sustenta no fragmento onde Benjamin diz que "o Reino de Deus não é o Telos da dinâmica histórica" (GAGNEBIN, 2014, pág.187). Sendo assim, ele não pode ser posto como meta. Neste sentido, historicamente ele não é meta mas fim. $O$ que significa que não estamos caminhando em direção a este fim, como acreditavam os sociais democratas e marxistas de sua época, em relação ao progresso que levaria a todos para o fim das contradições materiais e aboliria o capitalismo e seria o fim da sociedade de classes. Aqui o que está sendo 
dito é que, quando o mundo estiver pronto, quando todas as injustiças e sofrimentos tiverem sido rememorados e redimidos, o mundo se encontrará então liberto, e é aí que virá o Messias para restituir o Reino de Deus neste mundo, que agora redimido, portanto liberto, estará em condições de recebê-lo.

Para os dois autores salvo suas especificidades, uma questão fica acordada: para eles o tempo messiânico será inaugurado com o advento do Messias.

A nossa posição, por outro lado, é a de entender o verdadeiro estado de exceção, proposto enquanto Tempo Messiânico, como sendo o evento da revolução e não o seu desfecho. Diferentemente daqueles para quem o Tempo Messiânico se daria com a chegada do Messias, entendemos que este se inicia junto ao processo revolucionário que por sua vez teria seu auge, seu cume, sua realização, com a chegada do Messias, que restituiria assim a felicidade na terra.

Para isso nos atentamos a algumas passagens do próprio Benjamin nas quais acreditamos encontrar exatamente a confirmação de nossa hipótese. Uma delas encontra-se justamente na segunda tese, onde Benjamin fala da frágil força messiânica existente em nós. Frágil mas suficiente para darmos início ao processo revolucionário que libertará o mundo do sofrimento e da humilhação. Cabe ao homem essa revolução, cabe ao homem rememorar os sofrimentos do passado, resgatar cada tentativa de emancipação frustrada, onde dor e humilhação foram historicamente imputadas apenas aos derrotados. São seus nomes que precisam ser rememorados e suas lutas que precisam ser redimidas.

E se é o homem dotado dessa força messiânica, se cabe a ele fazer a revolução e expurgar o mundo de todo o sofrimento e injustiça, então é ele que vai instaurar o verdadeiro estado de exceção, que como havíamos apontado anteriormente terá seu auge, seu cumprimento, ou em outras palavras, sua realização de fato, na chegada do Messias, que abolirá o tempo histórico e instituirá o novo tempo do mundo.

O tempo messiânico se dará pelo homem, por que ele é parte do Messias e também por que cabe a ele limpar o mundo de todo o mal aqui já feito. Ainda na segunda tese Benjamin fala sobre uma ligação existente entre esta geração e a precedente, propondo que a atual geração estaria em uma espécie de dívida com a anterior, dívida histórica que enquanto não for rememorada, enquanto seus sofrimentos não forem redimidos, impedirá que a humanidade caminhe de fato para um mundo melhor. Pois enquanto o homem não aceitar sua responsabilidade por 
toda dor e sofrimento já causado, continuará mergulhado num mundo de injustiça e humilhação.

É o homem o protagonista desta história, é sua ação que dará início ao que será levado a termo pelo Messias. Em um de seus mais complexos e ao mesmo tempo reveladores textos, o Fragmento teológico político (2012), Benjamin fala do 'papel' do Messias no acontecer histórico. Se cabe ao homem o dever revolucionário, é dever do Messias consumar a libertação dos sofrimentos e injustiças cometidos: "só o próprio Messias consuma todo o acontecer histórico, nomeadamente no sentido de que só ele próprio redime, consuma, concretiza a relação desse acontecer com o Messiânico" (BENJAMIN 2012 p 23). Isso quer dizer que, se por um lado o homem é o responsável pela rememoração das injustiças do passado, por outro, a redenção delas será papel do Messias. Mais uma vez, será o homem que dará início à realização da felicidade na terra, mas ela só será efetivamente realizada pelo Messias.

Na sequencia desse texto, o autor fala da profunda ligação entre a 'ordem do profano' e a 'ideia de felicidade' que na junção com o messiânico, pra ele se constitui um 'dos axiomas essenciais da filosofia da história'. Vejamos o que ele quer dizer com isto. Para Benjamin a Felicidade se dará no momento da libertação do mundo, quando este mundo não conhecer mais o que é dor e sofrimento, quando estes sentimentos tiverem sido de fato redimidos, quando a distinção entre profano e sagrado não mais existir, desse modo sua filosofia da história se constitui por que é na busca dessa dor e sofrimento acontecidos no decurso histórico que será feita tal redenção. É nesse sentido que o messiânico e o histórico se cruzam e se realizam, sua ação é consequência e causa do outro.

Para iniciarmos a finalização e fazermos a devida ligação com o início do trabalho buscando deixar clara a nossa exposição, o que estamos querendo dizer é que, segundo nossa leitura, é com o início do processo revolucionário teremos de fato o verdadeiro estado de exceção, quando as normas serão suspensas para que seja possível fazer a rememoração e redenção do passado, para se ter o mundo livre de dor e humilhação e assim, ter-se o mundo pronto para a nova ordenação que será instaurada pelo Messias.

Benjamin defende a ideia de que nossa felicidade não se encontra no futuro como acredita todo historicista, mas se encontra na redenção do passado. Enquanto não se libertar o passado, não se instituir o verdadeiro estado de exceção, enquanto 
a locomotiva da revolução não sair da estação, não será possível a felicidade. 0 homem precisa se imbuir de sua força messiânica, instaurar o verdadeiro estado de exceção, inaugurar o tempo messiânico, para termos a felicidade terrena, pois enquanto isto não for feito, nem os mortos estarão em segurança.

Para finalizar citaremos uma passagem em que fica claro como Benjamin (a partir de Kafka) trata da vinda do Messias. Ele diz: "o Messias virá quando já não se precisa dele, virá um dia depois de sua chegada, não virá no último dia, mas no derradeiro" (GAGNEBIN, 2014).

Deste modo, não nos cabe outra conclusão se não a de que será o Messias que ratificará o tempo Messiânico, ele chegará para torná-lo efetivo, porém seu início se dará no momento em que a revolução for decretada, em que o verdadeiro estado de exceção se fizer, ou seja, no momento em que humanidade enfim der início ao trabalho de libertar o mundo.

\section{REFERÊNCIAS}

AGAMBEN, Giorgio; A Potência do Pensamento. Belo Horizonte: Autêntica, 2005.

Estado de exceção. São Paulo: Boitempo, 2004.

BARRENTO, João. Anjo da História. 2ª edição. Belo Horizonte: Autêntica, 2012.

BENJAMIN, Walter. Sobre o poder como violência. In: BARRENTO, João. Anjo da História. 2ª edição. Belo Horizonte: Autêntica, 2012.

. Teses Sobre Conceito de História. In: BARRENTO, João. Anjo da

História. 2ª edição. Belo Horizonte: Autêntica, 2012.

. Fragmento Teológico Político In BARRENTO, João; Anjo da História.

2ª edição. Belo Horizonte: Autêntica, 2012.

GAGNEBIN, Jeannie Marie. Limiar, aura e rememoração: ensaios sobre Walter Benjamin. São Paulo: Editora 34, 2014.

KAFKA, Franz. O Processo. São Paulo: Cia das Letras, 1997.

SCHIMITT, Carl; Teologia Política; Tradução: CONDE, Francisco Javier \& PEREZ, Jorge Navarro. Madri: Editora Trotta, 2009. 